\title{
(6) OPEN ACCESS \\ Global variations and time trends in the prevalence of childhood myopia, a systematic review and quantitative meta-analysis: implications for aetiology and early prevention
}

\author{
Alicja R Rudnicka, ${ }^{1}$ Venediktos V Kapetanakis, ${ }^{1}$ Andrea K Wathern, ${ }^{1}$ Nicola S Logan, ${ }^{2}$ \\ Bernard Gilmartin, ${ }^{2}$ Peter H Whincup, ${ }^{1}$ Derek G Cook, ${ }^{1}$ Christopher G Owen ${ }^{1}$
}

- Additional material is published online only. To view please visit the journal online (http://dx.doi.org/10.1136/ bjophthalmol-2015-307724)

'Population Health Research Institute, St George's, University of London, London, UK

${ }^{2}$ School of Life and Health Sciences, Aston University, Birmingham, UK

\section{Correspondence to} Dr Alicja R Rudnicka, Population Health Research Institute, St George's, University of London, Cranmer Terrace, London SW17 ORE, UK; arudnick@sgul.ac.uk

Received 21 August 2015 Revised 1 December 2015 Accepted 2 January 2016 Published Online First 22 January 2016



CrossMark

To cite: Rudnicka $A R$, Kapetanakis VV,

Wathern $\mathrm{AK}$, et al. $\mathrm{Br} \mathrm{J}$

Ophthalmol 2016;100

882-890.

\section{ABSTRACT}

The aim of this review was to quantify the global variation in childhood myopia prevalence over time taking account of demographic and study design factors. A systematic review identified population-based surveys with estimates of childhood myopia prevalence published by February 2015. Multilevel binomial logistic regression of log odds of myopia was used to examine the association with age, gender, urban versus rural setting and survey year, among populations of different ethnic origins, adjusting for study design factors. 143 published articles (42 countries, 374349 subjects aged 118 years, 74847 myopia cases) were included. Increase in myopia prevalence with age varied by ethnicity. East Asians showed the highest prevalence, reaching 69\% (95\% credible intervals (Crl) $61 \%$ to $77 \%$ ) at 15 years of age (86\% among Singaporean-Chinese). Blacks in Africa had the lowest prevalence; $5.5 \%$ at 15 years (95\% Crl 3\% to 9\%). Time trends in myopia prevalence over the last decade were small in whites, increased by $23 \%$ in East Asians, with a weaker increase among South Asians. Children from urban environments have 2.6 times the odds of myopia compared with those from rural environments. In whites and East Asians sex differences emerge at about 9 years of age; by late adolescence girls are twice as likely as boys to be myopic. Marked ethnic differences in age-specific prevalence of myopia exist. Rapid increases in myopia prevalence over time, particularly in East Asians, combined with a universally higher risk of myopia in urban settings, suggest that environmental factors play an important role in myopia development, which may offer scope for prevention.

\section{INTRODUCTION}

Myopia is the most common cause of correctable visual impairment in the developed world in adults and children ${ }^{1-5}$ and is a leading cause of preventable blindness in developing countries. ${ }^{6}$ Approximately one in six of the world's population is myopic. ${ }^{7}$ This represents a substantial burden worldwide with an appreciable unmet need for visual correction especially in poorer countries. ${ }^{8}$ Myopia begins in early life and increases in frequency and severity through childhood and adolescence into adulthood. High myopia affects up to $20 \%$ of secondary school children in East Asia, and is associated with sight-threatening pathologies that are irreversible. ${ }^{9}$ In white European populations the prevalence of myopia is relatively low affecting approximately $3-5 \%$ of 10 -year olds ${ }^{10-12}$ and up to $20 \%$ aged 12-13 years. ${ }^{2}{ }^{13-15}$ In contrast, studies from Asian populations suggest rapid increases in the prevalence of childhood myopia (in terms of prevalence and absolute levels of myopia), affecting 80-90\% of school-leavers in East Asia. ${ }^{9}$ 16-19 However, not all Asian populations appear to be undergoing this myopic transition. ${ }^{12} 20-23$ There are marked ethnic and geographical differences in myopia prevalence, which seem to have changed over time. There is a need to bring together the evidence to quantify population differences in myopia prevalence over time. However, quantifying the degree of ethnic differences in myopia is often hampered by interstudy differences in methodology, where different age groups, sampling methods and definitions of myopia are used. Hence, we undertook a systematic review of geographical and ethnic variations in myopia prevalence in childhood over an extended time period using a quantitative Bayesian meta-regression of studies that reported myopia prevalence. We provide estimates of myopia prevalence by age, ethnicity and sex, and examine trends over time. The influence of interstudy differences in study design on estimates of myopia prevalence was investigated as well as gender differences, and living in urban versus rural environments.

\section{METHODS}

The systematic review followed the Meta-analysis Of Observational Studies in Epidemiology guidelines for the conduct of systematic reviews and meta-analysis of observational studies. ${ }^{24}$ A combination of text words for myopia (short\$sight*/ myopi?/myope $\$$ /refractive error\$/ocular refraction), childhood (child/childhood/children/adolescent/ adolescence/teenage) and epidemiological terms (incident/incidence/prevalen*/population\$/survey\$) were combined with the related medical subject headings in MEDLINE (1950 to February 2015), and subject headings EMBASE (1980 to February 2015) and Web of Science (1970 to February 2015) databases (full search strategy is available in the online supplementary material). Validity of the search strategy was verified by its ability to identify all studies known to the investigators and those identified in recent qualitative reviews of myopia. 792526

\section{Inclusion and exclusion criteria}

Studies were included if they provided quantitative estimates of myopia prevalence in populations with 
a clearly defined sampling strategy. Surveys or audits of hospital eye departments or clinics were excluded. Studies that did not report ethnicity of the participants were excluded. Review articles were excluded to avoid duplication of data from individual studies, but were used to check that relevant studies were identified. Studies inviting non-specific volunteers, that relied on selfreported myopia or carried out refractive assessment in a subset, that is, only in those with reduced vision, were excluded.

\section{Studies identified and data extraction}

All data extraction was carried out independently by three reviewers (ARR, VVK and CGO), with independent extraction in a subset. Disagreements in data extraction were resolved by discussion.

Data were extracted on a number of key indicators of study quality, identified a priori. These included methods of assessment (including subjective refraction/retinoscopy and open or closed field autorefraction and use of cycloplegia) and case definition of myopia. In the presence of multiple definitions for myopia within a study, the definition with spherical equivalent refraction/sphere refraction closest to ' $-0.5 \mathrm{D}$ or less' was used. Some studies reported prevalence based on subjective refraction separately from those on autorefraction. In these situations we included only data from the autorefractor measurements to avoid double counting data from the same study. When prevalence was reported with and without the use of cycloplegia, estimates obtained after the use of cycloplegia were used preferentially.

Data were also extracted on study response rates, habitation type (urban, rural or mixed) and year of survey (midpoint when a study period was reported), geographical location (region/city and country), number of children examined, number with myopia, estimates of myopia prevalence by gender and ethnic/ racial group where available. For longitudinal studies, prevalence estimates from follow-up visits were not included in the analyses as our analyses are based on myopia prevalence not incidence.

Among studies that reported ethnicity, most studies were conducted on indigenous population groups (migrant populations were classified according to the reported ethnicity). Ethnicity was classified into the groups listed below, broadly following definitions of the United Nations (UN) and WHO:

I. Whites: individuals of white European ancestry residing in Europe, America, Australia and New Zealand

II. East Asian (eg, Chinese, Japanese, Mongolian, Taiwanese, and Chinese children in Hong Kong and Singapore)

III. South Asian (eg, Indian, Pakistani, Bangladeshi and Nepalese)

IV. South-East Asian (eg, Malaysian, Thai, Cambodian, Lao)

V. Blacks in Africa (eg, children from Burkina Faso, Madagascar, South Africa and Tanganyika)

VI. Blacks not in Africa (eg, blacks in UK or America)

VII. Middle Eastern or North African (eg, Iranian, Israeli, North African and Tunisian)

VIII. Hispanic or Latino (eg, Chilean, Colombian, Mexican, Puerto Rican and Ecuadorian)

IX. Native Hawaiian or other Pacific Islander (eg, Aborigines and children from Vanuatu)

X. American Indian or Alaska native

Ethnic specific estimates of prevalence were extracted if available; otherwise the reported prevalence of myopia was linked to the predominant ethnicity of the study population.

\section{Statistical analysis}

All statistical analyses were carried out using OpenBUGS $(\mathrm{V} .3 .2 .2)^{27}$ and R (V.3.1.1). ${ }^{28}$ We used Bayesian multilevel binomial logistic regression to investigate the associations between the log odds of myopia in either eye and potentially modifying factors, including age, gender, ethnicity, year of survey, and study design factors such as methods of assessment and habitation type.

Associations with age were non-linear and varied by ethnicity therefore the model allowed for a quadratic association with age that differed by ethnic group by including an interaction term in the models. Note, quadratic associations on the log odds scale translate into flexible non-linear associations on the prevalence scale, which encompass exponential associations with an asymptote. Ethnic specific time trends in reported myopia prevalence were investigated using year of survey.

Missing data on survey year were imputed for studies by subtracting 3 years from the year that the article was published (based on the median time to publication, in studies with available data). There were sufficient data to analyse time trends in whites, East Asians and South Asians only. We estimate ORs for rural versus urban and rural versus mixed habitation settings assuming a common OR across ethnicity; however we present sensitivity analyses by ethnicity.

We allowed for potential systematic differences between studies using different methods of refractive assessment by including study level covariates for the use of cycloplegia or not and whether refraction was based on (1) subjective refraction/ retinoscopy (this included studies that performed autorefraction and subjective refraction/retinoscopy) or (2) open field autorefraction or (3) closed field autorefraction. This investigation was performed on a subset of studies with available data adjusting for ethnic specific associations with age and survey year, as well as habitation type. Additional analyses investigated an interaction between age and use of cycloplegia.

The difference in myopia prevalence between boys and girls was estimated from a separate model using the subset of studies that reported data separately for boys and girls, adjusting for study design factors and ethnic specific associations with age. All analyses took into account the hierarchical data structure arising from repeated measures of prevalence within the same study population by fitting 'study population' as a 'level' in all our models. A study population was defined as the same ethnicity examined at the same point in time in the same geographical location. A full description of the model appears in the online supplementary statistical appendix. We present median prevalence estimates and ORs with 95\% credible intervals $(95 \%$ CrI), which represent the range of values within which the true value of an estimate is expected to lie with $95 \%$ probability.

Modelled age and ethnic specific prevalence estimates were standardised to urban populations and applied to UN demographic data for 2015 and $2025 .{ }^{29}$ We selected the dominant ethnic group for the following UN defined regions (1) BlackAfrica and the Caribbean, (2) White-Europe, North America, Western Asia, Australia and New Zealand, (3) HispanicCentral and Southern America, (4) Other/mixed-Melanesia, Micronesia and Polynesia. More detailed ethnic division was possible for Asia where (5) East Asian was used to represent Eastern and Central Asia, (6) South Asian-Southern Asia, and (7) South-East Asian-South-Eastern Asia. Using UN population data by 5 -year intervals (from 0 year to 19 years) the mid age band prevalence estimates at ages 2 years, 7 years, 12 years and 17 years were applied to the corresponding population data, to obtain population numbers with myopia, overall and by region, with associated $95 \%$ CrIs as described previously. ${ }^{30}$ A description of the statistical model is available online (see online supplementary statistical appendix). 


\section{RESULTS}

The article selection process is outlined in figure 1. In total 143 articles reported age-specific prevalence of myopia in 164 separate study populations (374 349 participants, 74847 cases of myopia) from cross-sectional surveys published between 1958 and 2015 in 42 different countries. Online supplementary table S1 summarises the key features of the articles contributing to this review along with the citation. Table 1 summarises the numbers of subjects and cases of myopia by ethnicity contributing to the analysis. Data extracted on myopia prevalence by ethnicity showed stark differences overall (figure 2) and a non-linear increase in myopia prevalence with age. We therefore modelled ethnic specific quadratic associations with age. There were sufficient data to estimate trends over time in myopia prevalence in whites, East Asians and South Asians only. Estimated over an extended time period there appears to have been a marginal decline in the odds of myopia in white children and adolescents after adjustment for age and environmental setting (estimates per decade in table 2). However, the 95\% CrI for this result is wide and compatible with stable myopia prevalence over time. In contrast, evidence suggests a 23\% increase per decade in East Asians (95\% CrI 1.00 to 1.55), with weak evidence of an increase in myopia prevalence over time in South Asians (table 2). There was no evidence to suggest that time trends were not linear. In addition, among East Asians time trends did not appear to vary by geographical location.

Table 3 provides estimates of myopia prevalence by age and ethnicity standardised to children residing in urban environments. For whites, East Asians and South Asians estimates are



Figure 1 Summary of article selection process from MEDLINE, EMBASE and Web of Science. also standardised to 2005. For other ethnic groups there were insufficient data to model time trends and therefore estimates are indicative of data available for the 'average' survey year given in tables 1. East Asians have the highest prevalence of myopia reaching $80 \%$ by 18 years of age. In contrast, the lowest myopia prevalence in late adolescence is in black children in Africa (5.5\% of 15 year olds).

Children living in predominantly urban environments have 2.6 times the risk of myopia compared with children living in rural environments (table 2, OR 2.61, 95\% CrI 1.79 to 3.86). Studies that reported prevalence for a mixed (urban+rural) population are a very heterogeneous group and the estimate should be interpreted with caution. There was no evidence of heterogeneity in the OR of urban versus rural environment by ethnicity. For all ethnic groups, except whites, an urban environment is associated with an increased risk of myopia, especially in blacks in Africa, South Asians and South-East Asians (figure 3). However, exclusion of one outlying study in western Newfoundland whites ${ }^{31}$ residing in a rural community weakened the OR for urban versus rural in whites to 0.99 (95\% CrI 0.26 to 5.01).

Studies that did not use cycloplegia reported double the odds of myopia than those that did use cycloplegia (after allowing for age, ethnicity, survey year and environmental setting, table 2). We examined an interaction between use of cycloplegia and age and found that the OR for 'no cycloplegia' versus cycloplegia was stronger at younger ages than at older ages (see online supplementary table S2). Method of measurement of refraction was also associated with myopia prevalence. Studies defining myopia based on autorefraction reported a higher prevalence of myopia (especially closed autorefraction) than studies using retinsocopy or subjective refraction (either exclusively or in addition to autorefraction).

The meta-regression comparing boys and girls is based on 64 study populations with 146996 participants and 36958 cases of myopia. We examined differences between boys and girls for each ethnic group separately. At about age 9 years gender differences begin to emerge in whites and East Asians and become more pronounced with age showing a higher prevalence of myopia in girls than in boys (see online supplementary table S3). By 18 years of age white girls are approximately twice as likely as white boys to be myopic (OR 2.03 95\% CrI 1.40 to 2.93). A similar picture emerged for East Asians (OR $2.3095 \%$ CrI 2.01 to 2.61). There was no clear evidence of gender differences in South Asians or in Hispanic/Latinos and there was insufficient data in the other ethnic groups to estimate gender differences by age.

There were sufficient data to investigate geographical variations in age-specific myopia prevalence in whites, East Asians and South Asians. In whites there was no clear evidence of differences in myopia prevalence in studies from Europe, USA and Oceania. Among East Asians the highest prevalence of myopia is among those residing in Singapore (86\% of 15 year olds, table 4). Rates are very similar in Hong Kong and Taiwan ( $\sim 80 \%$ of 15 year olds), lower in China ( $~ 59 \%$ of 15 year olds) and Australia ( $41 \%$ of 15 year olds). Rates are lowest in a rural population of Mongolia (table 4). Estimates in Japan are based on data from the 1990s and may not be representative of contemporary Japanese children. South Asian children residing in Australia, England or Singapore are approximately five times more likely to be myopic than their counterparts living in Nepal or India (table 4). At 15 years of age approximately $40 \%$ of migrant South Asians are myopic compared with $9 \%$ of indigenous South Asians. 
Table 1 Summary of the number of study populations with data on myopia prevalence by ethnic group

\begin{tabular}{|c|c|c|c|c|c|c|c|}
\hline \multirow[b]{2}{*}{ Ethnicity } & \multirow[b]{2}{*}{ No. study populations } & \multirow[b]{2}{*}{ Published articles } & \multirow[b]{2}{*}{ K } & \multirow[b]{2}{*}{$\mathbf{N}$} & \multirow[b]{2}{*}{$\mathbf{x}$} & \multicolumn{2}{|c|}{ Survey years } \\
\hline & & & & & & Range & Mean* \\
\hline White & 34 & 34 & 87 & 54324 & 3444 & 1958 to 2011 & 1994 \\
\hline East Asian & 65 & 55 & 310 & 157879 & 60895 & 1983 to 2013 & 2000 \\
\hline South Asian & 23 & 20 & 72 & 46012 & 2648 & 1992 to 2014 & 2002 \\
\hline South-East Asian & 9 & 7 & 18 & 19134 & 2076 & 1987 to 2010 & 2006 \\
\hline Black in Africa & 10 & 5 & 24 & 8491 & 262 & 1961 to 2009 & 1993 \\
\hline Black not in Africa & 5 & 5 & 15 & 5038 & 371 & 1997 to 2008 & 2006 \\
\hline Middle Eastern or North African & 16 & 16 & 67 & 41812 & 2679 & 1990 to 2011 & 2008 \\
\hline Hispanic or Latino & 10 & 10 & 26 & 33408 & 1503 & 1976 to 2007 & 1995 \\
\hline Native Hawaiian or other Pacific Islander & 6 & 6 & 15 & 5794 & 529 & 1967 to 2008 & 1987 \\
\hline American Indian or Alaska native & 4 & 4 & 9 & 2457 & 440 & 1967 to 2002 & 1985 \\
\hline Unknown/other/mixed & 3 & 3 & 3 & 323 & 42 & 2001 to 2008 & 2004 \\
\hline
\end{tabular}
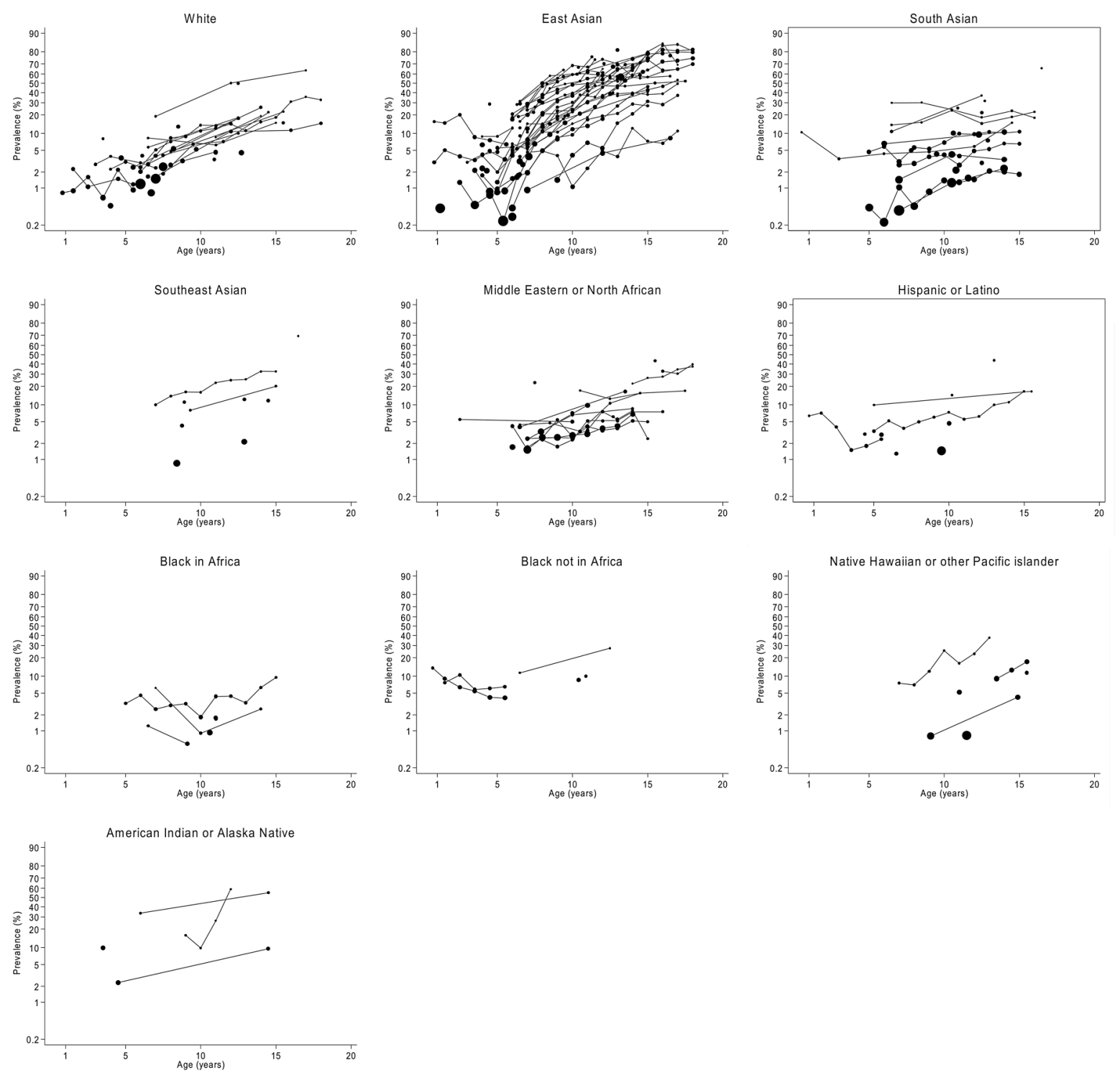

Figure 2 Prevalence (\%) of myopia for boys and girls combined by age and ethnic group. Data extracted on the age-specific prevalence (as a percentage) of myopia for all study populations are plotted against age for girls and boys combined, by ethnic group. The vertical axis is plotted on the logit scale. Data points from the same study population are joined by a straight line. The size of each symbol is inversely proportional to the SE of the estimate of prevalence. 
Table 2 ORs for trends over time, environmental setting and methods of refractive assessment

\begin{tabular}{|c|c|c|}
\hline Factor & $\begin{array}{l}\text { Number of } \\
\text { study } \\
\text { populations }\end{array}$ & $\begin{array}{l}\text { Adjusted odds ratio* } \\
\text { (95\% credible interval) }\end{array}$ \\
\hline \multicolumn{3}{|l|}{ Calendar Time } \\
\hline Per decade in whites & 34 & $0.85(0.69,1.05)$ \\
\hline Per decade in East Asians & 65 & $1.23(1.00,1.55)$ \\
\hline Per decade in South Asians & 23 & $1.05(0.45,2.63)$ \\
\hline \multicolumn{3}{|l|}{ Environmental setting } \\
\hline Rural & 37 & 1.00 \\
\hline Urban & 115 & $2.61(1.79,3.86)$ \\
\hline Mixed $t$ & 12 & $2.71(1.63,4.68)$ \\
\hline \multicolumn{3}{|l|}{ Study design characteristics } \\
\hline Cycloplegia-yes & 109 & 1.00 \\
\hline Cycloplegia-no & 43 & $2.12(1.76,2.52)$ \\
\hline Subjective refraction/retinoscopy & 85 & 1.00 \\
\hline Closed field autorefraction & 54 & $2.18(1.79,2.73)$ \\
\hline Open field autorefraction & 12 & $1.30(0.89,1.85)$ \\
\hline \multicolumn{3}{|c|}{$\begin{array}{l}\text { *ORs are the medians (95\% credible intervals in parenthesis) of the posterior } \\
\text { distributions from the Bayesian multilevel binomial logistic regression of the log odds } \\
\text { of myopia adjusting for ethnic specific associations with age, ethnic specific } \\
\text { associations with survey year (for white, East Asian and South Asian children, only) } \\
\text { and environmental setting. The multilevel model took into account that some study } \\
\text { populations provide only one age-specific estimate whereas others contribute data for } \\
\text { several age groups. ORs for the study design characteristics are based on a subset of } \\
\text { studies that specifically reported whether cycloplegia was used. ORs for } \\
\text { environmental setting and study design characteristics were assumed to be common } \\
\text { across ethnicities. } \\
\text { tMixed refers to studies that reported myopia prevalence for urban and rural groups } \\
\text { combined. }\end{array}$} \\
\hline
\end{tabular}

Estimates of the global myopia prevalence and number of cases by region were attained by applying modelled age and ethnic specific prevalence estimates to UN defined population data for calendar years 2015 and 2025 and ages 0 year to $<19$ years (see online supplementary table S4). Global estimates suggest a burden of 312 million myopic cases in 2015 (95\% CrI
265 million to 369 million), rising to 324 million (95\% CrI 276 million to 382 million) in 2025. Population prevalence of myopia in childhood ( 0 year to $<19$ years) is highest in East Asia (35\%) with nearly $80 \%$ of cases in Asia. The global share of myopia cases will remain high in Asia in 2025 with a marginal increase in Africa due to more rapid expansion of this age group in Africa than in other regions.

\section{DISCUSSION}

This is the first systematic review and quantitative meta-analysis of the worldwide prevalence of myopia in childhood and adolescence. We have quantified the striking ethnic differences in myopia prevalence that become more marked with age. In particular, East Asians show the highest prevalence with over 90\% of East Asians living in Singapore and $72 \%$ of East Asians living in China aged 18 years exhibiting myopia (defined as at least $-0.5 \mathrm{D}$ of myopia). Overall South Asians had much lower rates with limited evidence of trends over time. However, there were marked differences between those living in South Asia compared with migrant South Asian populations. There was no strong evidence of time trends in myopia prevalence among white populations. Non-linear associations between age and the log odds of myopia captured a large proportion of the ethnic variation in myopia prevalence. Some ethnic groups show a rapid increase with age in the early years that flattens (East Asians, whites, South Asians), suggesting that levels of myopia may have plateaued, reaching saturated levels. ${ }^{32}$ In others the increase in myopia prevalence was almost linear with age (South-East Asian, American Indian or Alaska Native, Native Hawaiian Pacific Islanders). In other groups the increase with age did not emerge until after about 8 years of age (Hispanics, blacks (in and outside of African) and Middle Eastern or North Africans). We have shown that living in an urban rather than rural environment is associated with almost a tripling in the risk of myopia and this pattern is seen among all ethnic groups. As expected, studies that did not use cycloplegia reported higher myopia prevalence (especially at younger ages) as did studies that relied

Table 3 Estimated prevalence of myopia by age and ethnicity in boys and girls combined

\begin{tabular}{|c|c|c|c|c|c|}
\hline \multirow[b]{2}{*}{ Ethnicity } & \multicolumn{4}{|c|}{ Prevalence (\%) of myopia by age } & \multirow{2}{*}{ Year } \\
\hline & 5 years & 10 years & 15 years & 18 years & \\
\hline White & $1.6(1.0,2.5)$ & $6.7(4.1,10.3)$ & $16.7(10.6,24.5)$ & $22.8(14.6,32.7)$ & $2005^{*}$ \\
\hline East Asian & $6.3(4.4,9.2)$ & $34.5(26.7,44.0)$ & $69.0(60.6,76.8)$ & $79.6(73.0,85.4)$ & $2005^{*}$ \\
\hline South Asian & $5.3(2.9,9.6)$ & $9.2(5.2,15.7)$ & $13.0(7.4,21.6)$ & $13.9(7.7,23.5) \dagger$ & $2005^{*}$ \\
\hline South-East Asian & $6.7(2.9,14.4) \ddagger$ & $11.5(5.3,23.3)$ & $23.7(11.7,41.8)$ & $28.0(13.8,48.2) \dagger$ & $2006 \S$ \\
\hline Black in Africa & $2.8(1.5,5.0)$ & $1.8(1.1,2.7)$ & $5.5(3.1,9.0)$ & & $1993 \S$ \\
\hline Black not in Africa & $4.8(4.0,5.7)$ & $8.2(6.8,9.8)$ & $19.9(14.3,26.5) 9$ & & $2006 \S$ \\
\hline Middle Eastern or North African & $3.5(2.0,5.7)$ & $5.5(3.4,8.8)$ & $19.6(12.8,28.6)$ & $47.1(34.2,60.4)$ & $2008 \S$ \\
\hline Hispanic or Latino & $5.0(1.9,11.6)$ & $4.7(1.8,11.0)$ & $14.3(5.8,29.8)$ & & $1995 \S$ \\
\hline Native Hawaiian or other Pacific Islander & $2.6(0.5,11.6) \ddagger$ & $5.5(1.4,20.3)$ & $23.0(6.9,57.6)$ & & $1987 \S$ \\
\hline American Indian or Alaska native** & $11.3(3.3,31.4)$ & $20.2(6.0,49.9)$ & $29.8(10.7,59.7)+\dagger$ & & $1985 \S$ \\
\hline
\end{tabular}

Prevalence estimates are medians ( $95 \%$ credible intervals in parenthesis) of the posterior distributions for predicted prevalence from the Bayesian multilevel binomial logistic regression of the log odds of myopia adjusting for ethnic specific associations with age, ethnic specific associations with survey year (for white, East Asian and South Asian children, only) and environmental setting. The multilevel model takes into account that some study populations provide only one age-specific estimate whereas others contribute data for several age groups.

Estimates correspond to urban populations.

* Survey year fitted in the model.

tEstimate at age 16.5 years (upper limit of available data).

\#Estimate at age 7 years (lower limit of available data)

$\S$ Mean survey year weighted by study population size.

IEstimate at age 12.5 years (upper limit of available data).

** Estimates correspond to rural populations as there were no data in an urban setting for this ethnic group.

t†Estimate at age 14.5 years (upper limit of available data). 
Ethnicity



Common odds ratio from Table 2

\section{Odds Ratio (95\% Crl)}

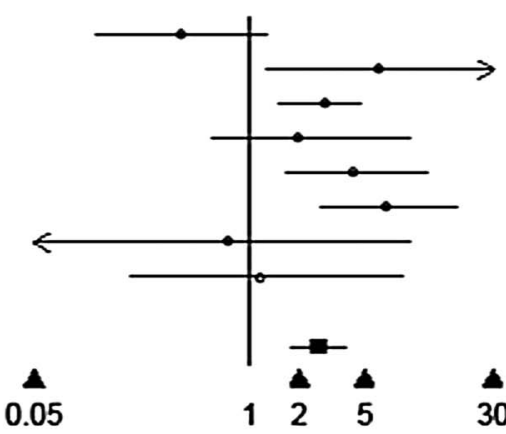

Odds Ratio (95\% Crl)

0.38 (0.12 to 1.27$)$

6.04 (1.27 to 46.6$)$

2.87 ( 1.53 to 4.66$)$

$1.96(0.60$ to 9.20$)$

4.21 (1.69 to 11.9$)$

6.69 (2.69 to 18.3$)$

$0.74(0.04$ to 9.23$)$

$1.16(0.19$ to 8.44$)$

2.61 (1.79 to 3.86$)$

\section{Urban setting beneficial Urban setting harmful}

Figure 3 ORs for urban versus rural setting are from a Bayesian multilevel binomial logistic regression stratified by ethnicity, adjusting for the quadratic association with age and year of survey (for white, East Asian and South Asian children, only). The common OR is from a Bayesian multilevel binomial logistic regression model using all the data from all ethnic groups combined that adjusts for the ethnic specific quadratic association with age, ethnic specific associations with survey year (for white, East Asian and South Asian children, only) and environmental setting, assuming common OR for urban versus rural settings across ethnicities (as presented in table 2).

on autorefractor findings, particularly closed field instruments. We also showed that sex difference in the age-specific prevalence of myopia exist in whites and East Asians, emerge at about 9 years of age and become more marked through adolescence showing double the odds of myopia in girls compared with boys.

The increase in myopia prevalence seen in urban compared with rural populations agrees with others that have explicitly examined this in children with the same ethnic ancestry. $202133-46$

Although there was no formal evidence of a difference in urban-rural differences across ethnic groups, some populations showed marginally larger ORs compared with others. Stronger urban-rural differences in South Asians and South-East Asians may reflect greater disparity in living conditions compared with high-income countries. These findings are consistent with the results of studies in population groups that migrate from rural to urban settings, which tend to adopt myopia rates of the host population, for example, Pacific Islanders that migrated to Taiwan; ${ }^{47}$ South Asian children living in the UK have higher rates of myopia ${ }^{12}$ than South Asian children residing in predominantly rural communities in India; ${ }^{21} 39$ Indians in Singapore have prevalence rates more similar to Singaporean Chinese than to Indians in India. ${ }^{48}$ The apparent decreased risk of myopia associated with urban environment in whites was explained by inclusion of western Newfoundland whites residing in a rural community with shared genetic ancestry, who showed an unusually high prevalence of myopia. ${ }^{31}$ Removal of this single

Table 4 Estimated prevalence of myopia by age in boys and girls combined (1) stratified by country for East Asians, and (2) stratified by continent for South Asians

\begin{tabular}{|c|c|c|c|c|c|}
\hline & \multicolumn{4}{|c|}{ Prevalence $(\%)$ of myopia by age } & \multirow[b]{2}{*}{ Year } \\
\hline & 5 years & 10 years & 15 years & 18 years & \\
\hline \multicolumn{6}{|l|}{ East Asians by country } \\
\hline Australia & $1.9(0.8,4.2)^{*}$ & $13.6(6.2,26.5)$ & $40.6(22.3,60.9)^{*}$ & - & $2005 t$ \\
\hline China & $3.9(2.9,5.9)$ & $24.9(19.8,34.3)$ & $59.0(51.7,69.3)$ & $71.9(65.4,80.0)^{*}$ & $2005 t$ \\
\hline Hong Kong & $9.2(5.4,15.7)$ & $45.3(31.8,60.7)$ & $78.2(66.8,87.1)$ & $86.4(78.2,92.2)^{*}$ & $2005 t$ \\
\hline Japan & $1.7(0.7,3.8)$ & $12.2(5.8,24.3)$ & $37.6(21.1,58.2)$ & $51.7(32.1,71.2)^{*}$ & $1990 \ddagger$ \\
\hline Malaysia & $4.6(1.4,14.5)^{*}$ & $28.4(10.4,58.1)$ & $63.2(33.5,85.7)$ & $75.3(47.2,91.4)$ & $1990 \ddagger$ \\
\hline Mongolia & $0.3(0.1,0.9) * \S$ & $2.7(0.8,7.2) \S$ & $10.8(3.5,25.0) \S$ & $17.7(5.9,37.2)^{\star} \S$ & $2003 \ddagger$ \\
\hline Singapore & $14.9(9.9,22.4)$ & $59.0(47.2,70.2)$ & $86.2(79.4,91.1)$ & $91.7(87.2,94.8)^{*}$ & $2005 t$ \\
\hline Taiwan & $10.1(5.9,19.8) \uparrow$ & $48.0(34.0,67.4)$ ๆ & $80.0(69.0,90.0) \emptyset$ & $87.6(79.9,94.0) \Re$ & $2005 t$ \\
\hline USA & $4.9(1.9,12.0)$ & - & - & - & $2005 t$ \\
\hline \multicolumn{6}{|l|}{ South Asians by continent } \\
\hline Living in South Asia & $3.6(2.2,5.7)$ & $6.4(4.0,9.7)$ & $9.1(5.7,13.7)$ & $10.3(5.8,17.0)^{*}$ & $2005 t$ \\
\hline Not living in South Asia & $20.4(10.6,36.0)^{*}$ & $31.6(17.8,50.1)$ & $40.5(24.1,59.5)$ & $43.8(25.2,63.9)^{*}$ & $2005 t$ \\
\hline \multicolumn{6}{|c|}{$\begin{array}{l}\text { Numbers express medians and } 95 \% \text { credible intervals in parenthesis. } \\
\text { Estimates correspond to urban populations standardised where possible to } 2005 \text {. For Japan and Malaysia, estimates are indicative of } 1990 \text { and for Mongolia estimates are for a rural } \\
\text { population in } 2003 \text {. } \\
\text { Cells without estimates of prevalence indicate insufficient data to obtain estimates. } \\
\text { *Estimate obtained by extrapolation. } \\
\text { tSurvey year as fitted in the model. } \\
\text { fMean survey year weighted by study population size. } \\
\text { §Estimates correspond to rural populations. }\end{array}$} \\
\hline
\end{tabular}


population reduced the OR for urban versus rural in whites towards the null.

Potential explanations have been suggested for the higher rates of myopia in children residing in urban settings compared with children from the same ethnic groups living in more rural settings including a more congested environment ${ }^{33} 44$ and greater emphasis on education and hence near vision activities. ${ }^{50-53}$ Several studies have shown a link between increased near vision activities and myopia, ${ }^{19} 385455$ but this is not a universal finding. ${ }^{11} 5657$ Years of education have also been related to myopia ${ }^{25}$ and introduction of formal education at younger ages in some East Asian countries ${ }^{57} 58$ may be a contributing factor. In Singapore ${ }^{59}$ children from as young as 3 years and as young as 2 years in Hong Kong ${ }^{32}$ actively participate in additional education classes before formal schooling education begins. In contrast, the prevalence of myopia is low in African populations where literacy rates are low, and formal education does not start for most children until the ages of 6-8 years. ${ }^{60}{ }^{61}$ It is possible that the younger age of initial exposure to formal education patterns levels of myopia through childhood.

Further evidence is provided by the reported independent associations of population density on myopia prevalence, ${ }^{33} 44$ which may suggest a contribution from a collection of risk factors associated with urban living environment. Time spent outdoors will differ between urban and rural communities and has been examined in relation to myopia. ${ }^{56}{ }^{58}{ }^{62-67}$ Children who become myopic are less likely to participate in sports/ outdoor activities. ${ }^{68}$ In a 2-year prospective study there was a suggestion that longer durations spent outdoors were associated with slower axial elongation in non-myopic teenagers but not in pre-existing myopes. ${ }^{69}$ A recent systematic review and meta-analysis showed a $2 \%$ reduction in the odds of myopia for every additional hour per week spent outdoors. ${ }^{70}$ Biological mechanisms for an association include low accommodative demand outdoors coupled with increased depth of focus. ${ }^{25}$ Time spent outdoors is also culturally patterned, and might be related to sibship; teasing out the independent, potentially causal, effects of time spent outdoors requires further study. ${ }^{62} 657172$

Despite the association between myopia prevalence and an urban environment, ethnic differences in myopia prevalence exist among populations drawn from the same living environment. ${ }^{12} 1454$ Whether these ethnic differences reflect genetic susceptibility to environmental factors or are due to ethnic differences in other factors is unclear. A previous meta-analysis of three British birth cohort studies including over 15000 white children showed that various familial factors were related to the odds of reduced vision (a proxy for myopia) in childhood including social class, parental education, maternal age and birth order (with higher risk among first-born children). ${ }^{10}$ All of these familial factors are likely to differ with level of urbanisation and ethnic group. It is also likely that intensity of near vision and emphasis on academic achievements are related to sibship and birth order.

Higher rates of myopia prevalence in girls compared with boys have been found in some individual studies, ${ }^{10} 1857$ 73-78 but not in others. ${ }^{12} 2123{ }^{79-81}$ The reason for disagreements between studies examining the association between myopia and sex is likely to be due to two factors (1) age of children studied, and (2) statistical power of a study which is influenced by the size of the study and the age-specific prevalence of myopia. The sex differences seem to emerge at about 9 years of age and become more pronounced with age, hence comparisons at younger ages are unlikely to show gender differences. Differences observed beyond the first decade of life have been attributed to a stronger emphasis on education/near distance related activities in girls compared with boys. ${ }^{18}$ This gender difference may persist in adulthood. ${ }^{5} 538283$ It is well established that differences between cycloplegic and non-cycloplegic refractions are more marked at younger ages, ${ }^{84-86}$ especially with closed field autorefraction. ${ }^{87}$

This review has a number of strengths and limitations. By adopting a more inclusive approach, we were able to include more studies in the meta-analysis thereby increasing the sample size and representativeness. Adopting a more exclusive approach, that is, omitting studies with imperfect study methods, would result in loss of power and would not allow study design differences to be quantified. We took account of study level factors including environmental setting, year of survey and survey methods used to define cases of myopia, particularly use of cycloplegia. The increased numbers allowed us to quantify the marked differences in the age-specific prevalence of myopia between ethnic groups, between urban and rural environments as well as gender differences. Limitations of this study include the omission of study response rates in the analysis as reliable data were not routinely reported. Our analysis is based on summaries from published data rather than data from individuals, which may lack the granularity to determine associations. A meta-analysis based on individual data would have yielded more precise results for the age-specific prevalence and could adjust for individual factors. Such an approach would be preferable if these data could be obtained for all relevant studies. However, the difficulty with an individual data meta-analysis is that it may represent a subset, biased towards well resourced studies, which are not representative of studies as a whole. Future work could examine trends in myopia incidence over time by meta-analysing estimates of incidence from longitudinal studies. This review did not examine within-person changes in spherical refraction over time which is likely to show different myopic refraction progression rates by ethnicity over time.

In summary, this meta-analysis provides the most comprehensive and current evidence on myopia prevalence in childhood and adolescence. It seems that populations that have experienced rapid economic transition (East and South Asians) have undergone the most rapid myopic transition. It will be important to monitor trends in myopia over time especially in relation to populations undergoing rapid transitions in myopia and to identify factors of the urban environment that are responsible. Understanding the aetiology of childhood myopia will give clues to prevention, potentially offering strategies to limit the economic impact of refractive error.

Collaborators All authors contributed substantially to the conception and design of this paper. ARR, VVK, AKW and CGO conducted the literature searches and extracted the data from published papers. ARR, VVK and CGO drafted the paper and carried out statistical analysis. All authors contributed to revising the manuscript and all authors approved the final version. ARR and CGO will act as guarantors. The guarantors accept full responsibility for the integrity of the work as a whole. All authors had access to the data, and approved the final version to be published.

Funding This work was supported by a grant from the BUPA Foundation (TBF-M10-034).

Disclaimer All researchers acted independently of study funders. The study funders played no role in study design and the collection, analysis, and interpretation of data and the writing of the article and the decision to submit it for publication. None of the funders influenced data analysis or interpretation of results. The comments made in this paper are those of the authors and not necessarily those of any funders.

Competing interests None declared. 
Open Access This is an Open Access article distributed in accordance with the Creative Commons Attribution Non Commercial (CC BY-NC 4.0) license, which permits others to distribute, remix, adapt, build upon this work non-commercially, and license their derivative works on different terms, provided the original work is properly cited and the use is non-commercial. See: http://creativecommons.org/ licenses/by-nc/4.0/

\section{REFERENCES}

1 Junghans B, Kiely PM, Crewther DP, et al. Referral rates for a functional vision screening among a large cosmopolitan sample of Australian children. Ophthalmic Physiol Opt 2002:22:10-25.

2 Kleinstein RN, Jones LA, Hullett $S$, et al. Refractive error and ethnicity in children. Arch Ophthalmol 2003:121:1141-7.

3 Lam CS, Goldschmidt E, Edwards MH. Prevalence of myopia in local and international schools in Hong Kong. Optom Vis Sci 2004;81:317-22.

4 Cumberland PM, Peckham CS, Rahi JS. Inferring myopia over the lifecourse from uncorrected distance visual acuity in childhood. Br J Ophthalmol 2007;91:151-3.

5 Foster PJ, Jiang Y. Epidemiology of myopia. Eye (Lond) 2014:28:202-8.

6 Congdon NG, Friedman DS, Lietman T. Important causes of visual impairment in the world today. JAMA 2003:290:2057-60.

7 Gilmartin B. Myopia: precedents for research in the twenty-first century. Clin Experiment Ophthalmol 2004;32:305-24.

8 Kempen $\mathrm{JH}$, Mitchell $\mathrm{P}$, Lee $\mathrm{KE}$, et al. The prevalence of refractive errors among adults in the United States, Western Europe, and Australia. Arch Ophthalmol 2004;122:495-505.

9 Morgan IG, Ohno-Matsui K, Saw SM. Myopia. Lancet 2012;379:1739-48.

10 Rudnicka AR, Owen CG, Richards $M$, et al. Effect of breastfeeding and sociodemographic factors on visual outcome in childhood and adolescence. Am J Clin Nutr 2008;87:1392-9.

11 Williams C, Miller LL, Gazzard G, et al. A comparison of measures of reading and intelligence as risk factors for the development of myopia in a UK cohort of children. Br J Ophthalmol 2008;92:1117-21.

12 Rudnicka AR, Owen CG, Nightingale CM, et al. Ethnic differences in the prevalence of myopia and ocular biometry in 10- and 11-year-old children: The child heart and health study in england (CHASE). Invest Ophthalmol Vis Sci 2010;51:6270-6.

13 O'Donoghue L, McClelland JF, Logan NS, et al. Refractive error and visual impairment in school children in Northern Ireland. $\mathrm{Br} J$ Ophthalmol 2010;94:1155-9.

14 Ip JM, Huynh SC, Robaei D, et al. Ethnic differences in refraction and ocular biometry in a population-based sample of 11-15-year-old Australian children. Eye 2008;22:649-56

15 Logan NS, Shah P, Rudnicka AR, et al. Childhood ethnic differences in ametropia and ocular biometry: the Aston Eye Study. Ophthalmic Physiol Opt 2011;31:550-8.

16 Saw SM. A synopsis of the prevalence rates and environmental risk factors for myopia. Clin Exp Optom 2003;86:289-94.

17 Saw SM, Goh PP, Cheng A, et al. Ethnicity-specific prevalences of refractive errors vary in Asian children in neighbouring Malaysia and Singapore. Br J Ophthalmol 2006;90:1230-5

18 Fan DSP, Lam DSC, Lam RF, et al. Prevalence, incidence, and progression of myopia of school children in Hong Kong. Invest Ophthalmol Vis Sci 2004;45:1071-5.

19 Quek TPL, Chua CG, Chong CS, et al. Prevalence of refractive errors in teenage high school students in Singapore. Ophthalmic Physiol Opt 2004;24:47-55.

20 Dandona R, Dandona L, Naduvilath TJ, et al. Refractive errors in an urban population in southern India: The Andhra Pradesh Eye Disease Study. Invest Ophthalmol Vis Sci 1999:40:2810-8.

21 Dandona $\mathrm{R}$, Dandona $\mathrm{L}$, Srinivas $\mathrm{M}$, et al. Refractive error in children in a rural population in India. Invest Ophthalmol Vis Sci 2002;43:615-22.

22 Kalikivayi V, Naduvilath TJ, Bansal AK, et al. Visual impairment in school children in Southern India. Indian J Ophthalmol 1997;45:129-34.

23 Murthy GVS, Gupta SK, Ellwein LB, et al. Refractive error in children in an urban population in New Delhi. Invest Ophthalmol Vis Sci 2002;43:623-31.

24 Stroup DF, Berlin JA, Morton SC, et al. Meta-analysis of observational studies in epidemiology: a proposal for reporting. Meta-analysis Of Observational Studies in Epidemiology (MOOSE) group. JAMA 2000;283:2008-12.

25 Morgan I, Rose K. How genetic is school myopia? Prog Retin Eye Res 2005:24:1-38.

26 Pan CW, Ramamurthy D, Saw SM. Worldwide prevalence and risk factors for myopia. Ophthalmic Physiol Opt 2012;32:3-16

27 Lunn D, Spiegelhalter D, Thomas A, et al. The BUGS project: evolution, critique and future directions. Stat Med 2009;28:3049-67.

28 R Core Team. R: A Language and Environment for Statistical Computing.R Foundation for Statistical Computing. Vienna, Austria. 2014. 21-4-2015

29 United Nations. World Population Prospects: The 2012 Revision.[ 2012 http://esa. un.org/wpp/unpp/panel_indicators.htm (accessed Sep 2014).

30 Kapetanakis VV, Chan MP, Foster PJ, et al. Global variations and time trends in the prevalence of primary open angle glaucoma (POAG): a systematic review and meta-analysis. $\mathrm{Br}$ J Ophthalmol 2016
31 Richler A, Bear JC. The distribution of refraction in 3 isolated communities in Western Newfoundland. Am J Optom Physiol Opt 1980:57:861-71.

32 Lam CS, Lam CH, Cheng SC, et al. Prevalence of myopia among Hong Kong Chinese schoolchildren: changes over two decades. Ophthalmic Physiol Opt 2012;32:17-24.

33 Ip JM, Rose KA, Morgan IG, et al. Myopia and the urban environment: findings in a sample of 12-year-old Australian school children. Invest Ophthalmol Vis Sci 2008:49:3858-63.

34 Yingyong P. Refractive errors survey in primary school children (6-12 year old) in 2 provinces: Bangkok and Nakhonpathom (one year result). J Med Assoc Thai 2010:93:1205-10.

35 Garner LF, Owens H, Kinnear RF, et al. Prevalence of myopia in Sherpa and Tibetan children in Nepal. Optom Vis Sci 1999:76:282-5.

36 Zhang MZ, Saw SM, Hong RZ, et al. Refractive errors in Singapore and Xiamen, China: a comparative study in school children aged 6 to 7 years. Optom Vis Sci 2000;77:302-8.

37 Lin LLK, Shih YF, Hsiao CK, et al. Epidemiologic study of the prevalence and severity of myopia among school children in Taiwan in 2000. J Formos Med Assoc 2001;100:684-91.

38 Saw SM, Hong RZ, Zhang MZ, et al. Near-work activity and myopia in rural and urban schoolchildren in China. J Pediatr Ophthalmol Strabismus 2001;38:149-55.

39 Khan AA, Nasti AR, Ayoub DM, et al. Prevalence of refractive errors in school children. JK Practitioner 2005;12:156-9

40 Fotouhi $A$, Hashemi $H$, Khabazkhoob $M$, et al. The prevalence of refractive errors among schoolchildren in Dezful, Iran. Br J Ophthalmol 2007;91:287-92.

41 Czepita D, Zejmo M, Mojsa A. Prevalence of myopia and hyperopia in a population of Polish schoolchildren. Ophthalmic Physiol Opt 2007;27:60-5.

42 Uzma N, Kumar BS, Khaja Mohinuddin Salar BM, et al. A comparative clinical survey of the prevalence of refractive errors and eye diseases in urban and rural school children. Can J Ophthalmol 2009:44:328-33.

43 Padhye AS, Khandekar R, Dharmadhikari S, et al. Prevalence of uncorrected refractive error and other eye problems among urban and rural school children. Middle East Afr J Ophthalmol 2009:16:69-74.

44 Zhang $\mathrm{M}$, Li L, Chen $\mathrm{L}$, et al. Population density and refractive error among Chinese children. Invest Ophthalmol Vis Sci 2010:51:4969-76.

45 Gao Z, Meng N, Muecke J, et al. Refractive error in school children in an urban and rural setting in Cambodia. Ophthalmic Epidemiol 2012:19:16-22.

46 Wu JF, Bi HS, Wang SM, et al. Refractive error, visual acuity and causes of vision loss in children in Shandong, China. The Shandong children eye study. PLOS ONE 2013:8:e82763.

47 Lin LLJ, Hung P-T, Ko L-S, et al. Study of myopia among aboriginal school children in Taiwan. Acta Ophthalmologica 1988;66(Suppl 185):34-6.

48 Au Eong KG, Tay TH, Lim MK. Race, culture and Myopia in 110,236 young Singaporean males. Singapore Med J 1993:34:29-32.

49 Wu HM, Seet B, Yap EP, et al. Does education explain ethnic differences in myopia prevalence? A population-based study of young adult males in Singapore. Optom Vis Sci 2001;78:234-9.

50 He MG, Zeng JW, Liu YZ, et al. Refractive error and visual impairment in urban children in southern China. Invest Ophthalmol Vis Sci 2004;45:793-9.

51 Shih YF, Chiang TH, Hsiao CK, et al. Comparing myopic progression of urban and rural Taiwanese schoolchildren. Jpn J Ophthalmol 2010;54:446-51.

52 Tay MT, Au Eong KG, Ng CY, et al. Myopia and educational attainment in 421,116 young Singaporean males. Ann Acad Med Singap 1992;21:785-91.

53 Williams KM, Bertelsen G, Cumberland P, et al. Increasing Prevalence of Myopia in Europe and the Impact of Education. Ophthalmology 2015;122:1489-97.

54 Saw SM, Chua WH, Hong CY, et al. Nearwork in early-onset myopia. Invest Ophthalmol Vis Sci 2002;43:332-9.

55 Mutti DO, Mitchell GL, Moeschberger ML, et al. Parental myopia, near work, schoo achievement, and children's refractive error. Invest Ophthalmol Vis Sci 2002;43:3633-40.

56 Ip JM, Saw SM, Rose KA, et al. Role of near work in myopia: findings in a sample of Australian school children. Invest Ophthalmol Vis Sci 2008:49:2903-10.

57 Lu B, Congdon N, Liu XJ, et al. Associations Between Near Work, Outdoor Activity, and Myopia Among Adolescent Students in Rural China The Xichang Pediatric Refractive Error Study Report No. 2. Archives of Ophthalmology 2009:127:769-75.

58 Rose KA, Morgan IG, Smith W, et al. Myopia, lifestyle, and schooling in students of Chinese ethnicity in Singapore and Sydney. Arch Ophthalmol 2008;126:527-30.

59 Dirani M, Chan Y-H, Gazzard G, et al. Prevalence of refractive error in Singaporean Chinese children: The Strabismus, Amblyopia, and Refractive Error in young Singaporean Children (STARS) study. Invest Ophthalmol Vis Sci 2010;51:1348-55.

60 Anera RG, Jimenez JR, Soler M, et al. Prevalence of refractive errors in school-age children in Burkina Faso. Jpn J Ophthalmol 2006:50:483-4.

61 Jimenez R, Soler M, Anera RG, et al. Ametropias in school-age children in Fada N'Gourma (Burkina Faso, Africa). Optom Vis Sci 2012:89:33-7.

62 Khader YS, Batayha WQ, Abdul-Aziz SM, et al. Prevalence and risk indicators of myopia among schoolchildren in Amman, Jordan. East Mediterr Health J 2006;12:434-9 
63 Saw SM, Shankar A, Tan SB, et al. A cohort study of incident myopia in Singaporean children. Invest Ophthalmol Vis Sci 2006;47:1839-44.

64 Jones LA, Sinnott LT, Mutti DO, et al. Parental history of myopia, sports and outdoor activities, and future myopia. Invest Ophthalmol Vis Sci 2007;48:3524-32.

65 Dirani M, Tong L, Gazzard G, et al. Outdoor activity and myopia in Singapore teenage children. Br J Ophthalmol 2009;93:997-1000.

66 Wu P-C, Tsai C-L, Hu C-H, et al. Effects of outdoor activities on Myopia among rural school children in Taiwan. Ophthalmic Epidemiol 2010;17:338-42.

67 Guggenheim JA, Northstone K, McMahon G, et al. Time outdoors and physical activity as predictors of incident myopia in childhood: a prospective cohort study. Invest Ophthalmol Vis Sci 2012;53:2856-65.

68 Jones-Jordan LA, Mitchell GL, Cotter SA, et al. Visual activity before and after the onset of juvenile myopia. Invest Ophthalmol Vis Sci 2011;52:1841-50.

69 Li SM, Li H, Li SY, et al. Time outdoors and myopia progression over 2 years in Chinese children: the anyang childhood eye study. Invest Ophthalmol Vis Sci 2015;56:4734-40.

70 Sherwin JC, Reacher MH, Keogh RH, et al. The association between time spent outdoors and myopia in children and adolescents: a systematic review and meta-analysis. Ophthalmology 2012;119:2141-51.

71 Deere K, Williams C, Leary S, et al. Myopia and later physical activity in adolescence: a prospective study. Br I Sports Med 2009;43:542-4.

72 Rose KA, Morgan IG, Ip J, et al. Outdoor activity reduces the prevalence of myopia in children. Ophthalmology 2008;115:1279-85.

73 Lin LLK, Shih YF, Tsai CB, et al. Epidemiologic study of ocular refraction among schoolchildren in Taiwan in 1995. Optom Vis Sci 1999;76:275-81.

74 Zadnik K, Manny RE, Yu JA, et al. Ocular component data in schoolchildren as a function of age and gender. Optom Vis Sci 2003;80:226-36.

$75 \mathrm{He} \mathrm{M}, \mathrm{Xu}$ J, Yin Q, et al. Need and challenges of refractive correction in urban Chinese school children. Optom Vis Sci 2005;82:229-34.
76 He MG, Huang WY, Zheng YF, et al. Refractive error and visual impairment in school children in rural southern China. Ophthalmology 2007;114:374-82.

77 Goh P-P, Abqariyah Y, Pokharel GP, et al. Refractive error and visual impairment in school-age children in Gombak District, Malaysia. Ophthalmology 2005;112:678-85.

78 Zhang M, Gazzard G, Fu Z, et al. Validating the accuracy of a model to predict the onset of myopia in children. Invest Ophthalmol Vis Sci 2011;52:5836-41.

79 Pokharel GP, Negrel AD, Munoz SR, et al. Refractive error study in children: results from Mechi Zone, Nepal. Am J Ophthalmol 2000;129:436-44.

80 Maul E, Barroso S, Munoz SR, et al. Refractive error study in children: results from La Florida, Chile. Am J Ophthalmol 2000;129:445-54.

81 Naidoo KS, Raghunandan A, Mashige KP, et al. Refractive error and visual impairment in African children in South Africa. Invest Ophthalmol Vis Sci 2003;44:3764-70.

82 Rahi JS, Cumberland PM, Peckham CS. Myopia over the lifecourse: prevalence and early life influences in the 1958 British birth cohort. Ophthalmology 2011;118:797-804.

83 Wong TY, Foster PJ, Hee J, et al. Prevalence and risk factors for refractive errors in adult Chinese in Singapore. Invest Ophthalmol Vis Sci 2000;41:2486-94.

84 Farhood QK. Cycloplegic refraction in children with cyclopentolate versus atropine. J Clin Exp Ophthalmol 2012;3:239.

85 Williams C, Miller L, Northstone K, et al. The use of non-cycloplegic autorefraction data in general studies of children's development. Br J Ophthalmol 2008;92: 723-4.

86 Zhao J, Mao J, Luo R, et al. Accuracy of noncycloplegic autorefraction in school-age children in China. Optom Vis Sci 2004;81:49-55.

87 Choong YF, Chen AH, Goh PP. A comparison of autorefraction and subjective refraction with and without cycloplegia in primary school children. Am J Ophthalmol $2006 ; 142: 68-74$. 